\title{
Postoperative real-time electrocardiography monitoring detects myocardial ischemia: a case report
}

\section{Le monitorage électrocardiographique postopératoire en temps réel pour détecter l'ischémie myocardique: une présentation de}

\section{cas}

\author{
Homer Yang, MD - Ashraf Fayad, MD • Alan Chaput, MD • Stuart Oake, MD • \\ Adrian D. C. Chan, PhD • Mary Lou Crossan, BA
}

Received: 20 August 2016/Revised: 23 November 2016/Accepted: 1 January 2017/Published online: 11 January 2017

(C) Canadian Anesthesiologists' Society 2017

\begin{abstract}
Purpose This case report outlines the utility and challenges of remote continuous postoperative electrocardiography ECG) monitoring, which is routed through a secure smartphone to provide real-time detection and management of myocardial ischemia.

Clinical features $A$ 42-yr-old male with previous myocardial infarction and angioplasty underwent a radical prostatectomy. At three hours and $45 \mathrm{~min}$ postoperatively, remote real-time ECG monitoring was initiated upon the patient's arrival on a regular surgical ward. Monitor alerts were routed to a study clinician's smartphone. About six hours postoperatively, alarms were received and horizontal ST segment depressions were observed. A 12-lead ECG validated the ST segment changes, prompting initiation of a metoprolol iv and a red blood cell transfusion. Approximately seven hours and 30 min postoperatively, the ST segments normalized. The patient was discharged on postoperative day 3 and followed for four years without any sequelae.

Conclusion This case report illustrates the use of remote ECG monitoring and clinician response in real time with
\end{abstract}

H. Yang, MD $(\bowtie) \cdot$ A. Fayad, MD · A. Chaput, MD .

M. L. Crossan, BA

Department of Anesthesia, The Ottawa Hospital, University of Ottawa, Ottawa, ON, Canada

e-mail: hyang@toh.ca

S. Oake, MD

Division of Urology, Department of Surgery, The Ottawa

Hospital, University of Ottawa, Ottawa, ON, Canada

A. D. C. Chan, $\mathrm{PhD}$

Department of Systems and Computer Engineering, Carleton

University, Ottawa, ON, Canada the use of a smartphone. With each alert, a small ECG strip is transmitted to the smartphone for viewing. In our view, this technology and management system provides a possible means to interrupt myocardial ischemic cascades in real time and prevent postoperative myocardial infarction.

Résumé

Objectif Cette présentation de cas décrit l'utilité et les défis d'un monitorage électrocardiographique (ECG) postopératoire continu à distance, dont le signal est acheminé via un téléphone intelligent sécurisé pour permettre la détection et la prise en charge en temps réel de l'ischémie myocardique.

Éléments cliniques Un homme de 42 ans présentant des antécédents d'infarctus du myocarde et d'angioplastie a subi une prostatectomie radicale. Trois heures et 45 minutes après l'opération, un monitorage ECG en temps réel a été lancé à distance, soit à l'arrivée du patient dans un service régulier de chirurgie. Les alertes du moniteur ont été acheminées vers le téléphone intelligent d'un clinicien de l'étude. Après environ six heures postopératoires, des signaux ont été reçus et des sous-décalages horizontaux du segment ST observés. Un ECG à 12 dérivations a permis de valider les changements au segment ST, incitant l'amorce d'une iv de métoprolol et une transfusion d'érythrocytes. Approximativement sept heures et 30 minutes après l'opération, les segments ST se

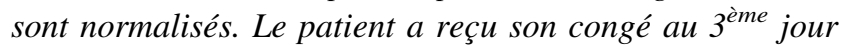
postopératoire, puis il a été suivi pendant quatre ans sans séquelles.

Conclusion Cette présentation de cas illustre l'utilisation d'un monitorage ECG à distance et la réponse du clinicien en temps réel à l'aide de son téléphone intelligent. Lors de 
chaque alerte, une petite bande de rythme ECG est transmise au téléphone intelligent pour être visionnée. Selon nous, cette technologie et ce système de gestion offrent une possibilité d'interrompre les cascades d'ischémie myocardique en temps réel et de prévenir l'infarctus du myocarde postopératoire.

This case report illustrates the use of remote continuous postoperative electrocardiography (ECG) monitoring, which is routed through a smartphone to provide detection and initiate clinical management of myocardial ischemia. It was part of a feasibility observational trial, PROSE 3 (Clinicaltrials.gov NCT01423136), in which 89 patients were enrolled and 69 completed the study. Electrocardiogram ST segment analysis during Holter monitoring has been studied prior to, during, and after surgery, ${ }^{1-3}$ but only the postoperative ST segment changes were associated with postoperative ischemic cardiac events in a multivariate analysis model. ${ }^{2}$ Postoperative myocardial ischemia can be treated by decreasing heart rate reductions, thereby interfering with the myocardial ischemic cascade. ${ }^{4,5}$ Nevertheless, as postoperative ECG analysis is typically performed offline, days after the associated myocardial ischemic event, timely treatment is not possible. To address this shortcoming, PROSE 3 was conducted to examine the feasibility of real-time ST segment analysis as demonstrated with this case.

\section{Clinical features}

A 42-yr-old male (weight, $83 \mathrm{~kg}$; height, $163 \mathrm{~cm}$ ) was scheduled for open elective radical prostatectomy with bilateral pelvic lymphadenectomy. Prior to surgery, the patient had consented to remote real-time ECG monitoring as part of the PROSE 3 trial. His medical history included a myocardial infarction in 2002, coronary angioplasty in 2006, hypertension, and class II angina. His daily medications prior to surgery included $75 \mathrm{mg}$ venlafaxine, $20 \mathrm{mg}$ rosuvastatin, $25 \mathrm{mg}$ hydrochlorothiazide, and 100 $\mathrm{mg}$ metoprolol bid. Cardiology was consulted prior to surgery and no further optimization was deemed necessary. Preoperative hemoglobin was $139 \mathrm{~g} \cdot \mathrm{L}^{-1}$ and the 12-lead ECG was unremarkable. Spinal anesthesia and analgesia were achieved with $0.5 \%$ bupivacaine $10 \mathrm{mg}$ with intrathecal preservative-free morphine $200 \mu \mathrm{g}$ as per institutional protocol. Standard monitoring included noninvasive blood pressure, ECG (leads II and V5), and pulse oximetry. ${ }^{6}$ General anesthesia was induced with propofol $90 \mathrm{mg}$, fentanyl $150 \mu \mathrm{g}$, and rocuronium $45 \mathrm{mg}$ and maintained with desflurane, oxygen, air, and repeated doses of fentanyl to a maximum of $225 \mu \mathrm{g}$. Surgery was uneventful and lasted two hours 33min. The estimated blood loss was $385 \mathrm{~mL}$, and normal saline $2,073 \mathrm{~mL} i v$ was given intraoperatively. Reversal of muscle paralysis was achieved with neostigmine $1.5 \mathrm{mg}$ and glycopyrrolate 0.2 mg. In the postanesthesia care unit (PACU), blood loss from surgical drains was $50 \mathrm{~mL}$; intravenous administration included normal saline $390 \mathrm{~mL}$ iv and Voluven ${ }^{\circledR} 500 \mathrm{~mL} i v$. The patient's stay in the PACU was uneventful, and he was discharged to a standard surgical ward at 19:37, three hours and $45 \mathrm{~min}$ postoperatively. Remote real-time heart rate and ST segment monitoring was then initiated via antenna pickup connected to a Spacelabs Ultraview monitor (Spacelabs Healthcare Canada, Mississauga, ON, Canada) with full disclosure settings. Leads II and V5 were monitored, with ST depression measured at $0.06 \mathrm{sec}$ after the $\mathrm{J}$ point. Changes of at least $1 \mathrm{~mm}$ in amplitude lasting longer than ten minutes were considered significant. Heart rate alarm limits were set to $<50$ and $>120$ beats $\cdot \mathrm{min}^{-1}$. Electrocardiogram heart rate and ST alarms were routed to the study clinician's smartphone via secured hospital email (Fig. 1).

Within a five-hour 56min interval (19:38-01:34) 22 false heart rate alarms were received, with an upsloping ST depression $<1 \mathrm{~mm}$. These were considered to be motion artifacts after the study clinician reviewed them in real time. During this interval, the patient was regularly checked and assessed to be doing well. His vital signs recorded at midnight were blood pressure $135 / 77 \mathrm{mmHg}$, heart rate 98 beats. $\mathrm{min}^{-1}$ and regular, and pulse oximetry $\mathrm{SpO}_{2}$ 98\%. During 01:54-02:09 AM, however, two ST alarms were received on the clinician's smartphone, showing horizontal ST segment depressions that gradually increased from -1.12 to $-1.84 \mathrm{~mm}$ (Fig. 2). At 1:54 $\mathrm{AM}$, a heart rate of 127 beats. $\mathrm{min}^{-1}$ also triggered a heart rate alarm. Upon request by the study clinician, the nurse checked the patient at 02:15 AM, who assessed the patient to be sleeping "comfortably" and easily aroused. There was no complaint of chest pain and the nurse did not notice any cyanosis. It was noticed, however, that the patient did not receive his evening dose of metoprolol. The study clinician notified the on-call surgical and anesthesia personnel at 02:20. Subsequently, a 12-lead ECG, complete blood count (CBC), blood chemistry, and troponin I tests were ordered. Oxygen via nasal prongs was administered. The 12-lead ECG showed a heart rate of 88 beats. $\mathrm{min}^{-1}$ with new $\mathrm{T}$ wave inversions and $\mathrm{Q}$ waves inferiorly. Metoprolol $10 \mathrm{mg} i v$ was given in 1-mg increments titrated to maintain the patient's heart rate at $60-80$ beats $\cdot \mathrm{min}^{-1}$. The CBC showed a drop in hemoglobin from $102 \mathrm{~g} \cdot \mathrm{L}^{-1}$ (postoperatively) to $85 \mathrm{~g} \cdot \mathrm{L}^{-1}$, and one unit of packed red 


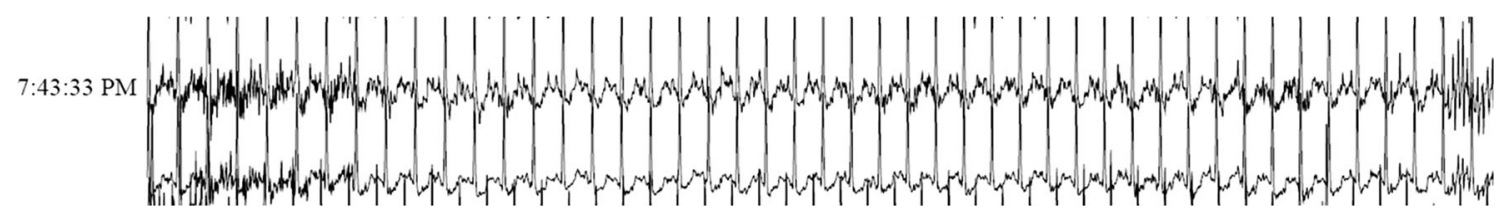

Fig. 1 Electrocardiogram monitoring received remotely via smartphone at 19:43 after the patient arrived on the surgical ward. Leads II and V5 (upper and lower traces, respectively) were monitored. No alarm condition

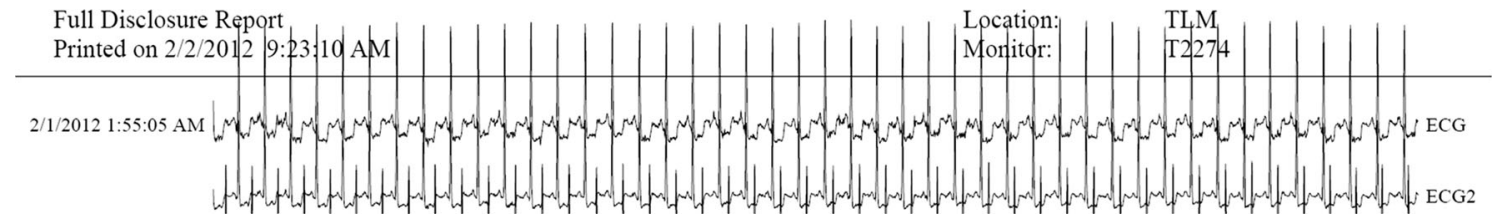

Fig. 2 Electrocardiogram monitoring received remotely via smartphone at 01:55 showing ST segment depression $(-1.12 \mathrm{~mm})$ accompanied by alert. $\mathrm{ECG}=$ electrocardiogram

blood cells was transfused (hemoglobin $88 \mathrm{~g} \cdot \mathrm{L}^{-1}$ following the transfusion). At 04:19, ST segments normalized and heart rate was maintained at $60-80$ beats $\cdot \mathrm{min}^{-1}$. Cardiology service was consulted. Although they were unavailable to see the patient until later in the morning, no further actions were deemed necessary and they supported our assessment of supply-demand ischemia. The patient was discharged three days postoperatively and has been without cardiacrelated problems for over four years.

\section{Discussion}

This case shows how technology can link clinicians to a changing clinical situation in real-time, enabling provision of appropriate and timely medical care. Technology helped to alert the perioperative team so that a potentially serious cardiac ischemic event could be appropriately interrupted. Importantly, during the ischemic event, the patient did not experience any untoward symptoms, and standard patient care on the surgical ward was insufficient to identify the evolving cardiac event. Such real-time ECG monitoring differs from previous efforts using Holter monitoring which provides information that is time delayed by hours or days. The remote monitoring, as described, also differs from traditional telemetry, which is available only in specialized locations, such as step-down, intensive care, or cardiac care units. Moreover, the integration of telemetry into these sites requires extensive nursing training and continuing education.

Indeed, telemetry monitoring for ST segment changes has been used after acute coronary syndromes and coronary artery interventions, ${ }^{7}$ but it remains an underutilized technology even in these circumstances. ${ }^{8}$ Postoperative ST segment monitoring via telemetry after non-cardiac surgery is even rarer, and its availability on surgical wards is unknown. ${ }^{7}$ While remote ECG monitoring technology has existed for some time, there is a lack of literature concerning its use for remote real-time off-site monitoring or on regular surgical wards during the postoperative period. Nevertheless, some studies have been published concerning its use in the intensive care unit, ${ }^{9-13}$ including during weaning from mechanical ventilation. ${ }^{14-17}$ Importantly, none of those studies involved remote offsite monitoring.

An important consideration for remote patient monitoring is ensuring that the technology provides the appropriate documentation, privacy, and firewall protection befitting a medical recording and transmission system. Our system has de-identified encrypted e-mail transmissions, emails stored behind the firewall, full disclosure behind the firewall, and "double-lock" data storage as per Research Ethics Board requirements. One of the drawbacks of remote cardiac monitoring is the relatively large number of false alarms, and this continues to be a challenge with this emerging technology. During the $24 \mathrm{hr}$ of monitoring with the patient described in this report, there were 60 false alarms and three true alarms. Causes for false alarms include motion artifacts, electrolyte shifts, temperature changes, and tachycardia. ${ }^{18}$ In addition, there are biomedical engineering reasons for false alarm triggers, and work in progress on signal quality index and signal-tonoise ratio has shown improvements in alarm algorithms. ${ }^{19-21}$

Postoperative myocardial infarction is one of the most frequent and serious adverse events. ${ }^{22}$ In a study of vascular patients, the overall mortality was $3.4 \%$, and seven of eight deaths were related to perioperative myocardial ischemic injury (PMII). Of 236 patients, PMII occurred in 42 (17.8\%) patients: 22 myocardial 
infarctions, 11 congestive heart failures, and 12 new arrhythmias (three patients had two PMII events). The mean hospital length of stay was 16.8 and 10.0 days for patients with and without PMII, respectively $(P<0.001) .^{23}$ In a study of patients $\geq 60 \mathrm{yr}$ of age, 129/1,422 (9.1\%) developed at least one major adverse cardiac event, and cardiac death occurred in 11 patients $(0.8 \%){ }^{24}$

With the patient described in the present report, the combination of perioperative blood loss, a missed evening metoprolol dose, and tachycardia undoubtedly contributed to the evolving cardiac ischemic cascade. The synergistic combination of missing postoperative beta-blocker doses and bleeding on myocardial ischemia has been previously described. ${ }^{25}$ The rebound effect of increased heart rate and contractility after missing a beta-blocker dose in the postoperative period, combined with postoperative anemia, is likely a factor leading to an imbalance of myocardial oxygen supply and demand and the resulting ischemia. An acute coronary syndrome may be the result of plaque rupture (type 1) or an imbalance of supply and demand (type 2), ${ }^{22}$ and the ensuing ischemic cascade ${ }^{26}$ may be interrupted by early intervention. In this case, the troponin I rose to only $0.05 \mu \mathrm{g} \cdot \mathrm{L}^{-1}$ and no new ECG changes persisted, so it is unlikely that the patient experienced a postoperative myocardial infarction. In view of the specificity of postoperative myocardial ischemia in predicting myocardial ischemic complications, we assume that the early intervention to interrupt the ischemic cascade prevented a likely postoperative myocardial infarct. ${ }^{2,10}$

In conclusion, this case report illustrates the usefulness of real-time remote monitoring of ECG signals recorded from hospitalized patients at risk of cardiac events. This case involved a postoperative surgical patient who experienced electrocardiographic evidence of myocardial ischemia during his recovery on a standard surgical floor. The patient was otherwise asymptomatic. The ECG monitoring, as described, allowed for timely detection and appropriate clinical intervention, otherwise that would not have occurred. Real-time remote ECG monitoring during the postoperative period is a potentially useful tool to help prevent perioperative myocardial infarction.

\begin{abstract}
Acknowledgement This observational trial was funded by The Ottawa Hospital Academic Medical Organization as part of the initiative of the Ontario Ministry of Health Alternative Funding Plan/ Innovation Fund Provincial Oversight Committee. We would also like to state that there was no financial conflict of interest in this project. We express our appreciation to Spacelabs for their invaluable advice regarding this project.
\end{abstract}

Conflicts of interest None declared.

Editorial responsibility This submission was handled by Dr. Steven Backman, Associate Editor, Canadian Journal of Anesthesia.
Author contributions Homer Yang was the principal author and principal investigator of the PROSE 3 project. Alan Chaput, Ashraf Fayad, and Stuart Oake were co-authors. Alan Chaput and Ashraf Fayad were co-investigators of PROSE 3. Alan Chaput contributed substantially to the initial PROSE 3 protocol and to writing the case report. Ashraf Fayad contributed substantially to the conception and design of PROSE 3. Ashraf Fayad and Stuart Oake contributed substantially to writing the manuscript. Stuart Oake contributed substantially to the design of the manuscript. Mary Lou Crossan was the research assistant. She contributed to patient recruitment, study conduct, and data acquisition for PROSE 3, all of which led to this case report.

\section{References}

1. Raby KE, Barry J, Creager MA, Cook EF, Weisberg MC, Goldman L. Detection and significance of intraoperative and postoperative myocardial ischemia in peripheral vascular surgery. JAMA 1992; 268: 222-7.

2. Mangano DT, Browner WS, Hollenberg M, London MJ, Tubau $J F$, Tateo IM. Association of perioperative myocardial ischemia with cardiac morbidity and mortality in men undergoing noncardiac surgery. The Study of Perioperative Ischemia Research Group. N Engl J Med 1990; 323: 1781-8.

3. Mangano DT, Hollenberg M, Fegert $G$, et al. Perioperative myocardial ischemia in patients undergoing noncardiac surgeryI: incidence and severity during the 4 day perioperative period. The Study of Perioperative Ischemia (SPI) Research Group. J Am Coll Cardiol 1991; 17: 843-50.

4. Raby KE, Brull SJ, Timimi F, et al. The effect of heart rate control on myocardial ischemia among high-risk patients after vascular surgery. Anesth Analg 1999; 88: 477-82.

5. Landesberg G, Luria MH, Cotev S, et al. Importance of longduration postoperative ST-segment depression in cardiac morbidity after vascular surgery. Lancet 1993 ; 341: 715-9.

6. Merchant $R$, Chartrand D, Dain $S$, et al. Guidelines to the practice of anesthesia - revised edition 2016. Can J Anesth 2016, 63: 86-112.

7. Drew BJ, Califf RM, Funk $M$, et al. AHA scientific statement: practice standards for electrocardiographic monitoring in hospital settings: an American Heart Association Scientific Statement from the Councils on Cardiovascular Nursing, Clinical Cardiology, and Cardiovascular Disease in the Young: endorsed by the International Society of Computerized Electrocardiology and the American Association of Critical-Care Nurses. J Cardiovasc Nurs 2005; 20: 76-106.

8. Patton JA, Funk M. Survey of use of ST-segment monitoring in patients with acute coronary syndromes. Am J Crit Care 2001; 10: 23-32; quiz 33-4.

9. Karapandzic VM, Vujisic-Tesic BD, Pesko PM, Nenadic BM, Babic DD. The effect of metoprolol on perioperative outcome in coronary patients undergoing nonvascular abdominal surgery. $\mathrm{J}$ Clin Anesth 2008; 20: 284-9.

10. Landesberg G, Mosseri M, Zahger D, et al. Myocardial infarction after vascular surgery: the role of prolonged stress-induced, ST depression-type ischemia. J Am Coll Cardiol 2001; 37: 1839-45.

11. Martinez EA, Kim LJ, Faraday N, et al. Sensitivity of routine intensive care unit surveillance for detecting myocardial ischemia. Crit Care Med 2003; 31: 2302-8.

12. Sbarigia E, DarioVizza $C$, Antonini $M$, et al. Locoregional versus general anesthesia in carotid surgery: is there an impact on perioperative myocardial ischemia? Results of a prospective monocentric randomized trial. J Vasc Surg 1999; 30: 131-8. 
13. Upriamova E, Kozlov SP, Klimenko VS, Stamov VI, Svetlov VA. New possibilities of complex monitoring of the cardiovascular system during thoraco-abdominal surgeries (Russian). Anesteziol Reanimatol 2011; 3: 13-8.

14. Abalos A, Leibowitz AB, Distefano D, Halpern N, Iberti TJ. Myocardial ischemia during the weaning period. Am J Crit Care 1992; 1: 32-6.

15. Chatila W, Ani S, Guaglianone D, Jacob B, Amoateng-Adjepong $Y$, Manthous $C A$. Cardiac ischemia during weaning from mechanical ventilation. Chest 1996; 109: 1577-83.

16. Srivastava $S$, Chatila W, Amoateng-Adjepong $Y$, et al. Myocardial ischemia and weaning failure in patients with coronary artery disease: an update. Crit Care Med 1999; 27: 2109-12.

17. Hurford WE, Favorito $F$. Association of myocardial ischemia with failure to wean from mechanical ventilation. Crit Care Med 1995; 23: 1475-80.

18. Yang $H$. Intraoperative automated ST segment analysis: a reliable 'black box'? Can J Anaesth 1996; 43: 1041-51.

19. Quesnel $P X$, Chan $A D$, Yang $H$. Signal quality and false myocardial ischemia alarms in ambulatory electrocardiograms. IEEE International Symposium on Medical Measurements and Applications; Lisbon, Portugal 2014. Available from URL: http:// www.gbv.de/dms/tib-ub-hannover/79886060x.pdf (accessed November 2016).

20. Abdelazez M, Quesnel PX, Chan AD, Yang $H$. Signal quality indices for ambulatory electrocardiograms used in myocardial ischemia monitoring. World Congress on Medical Physics and Biomedical Engineering 2015; 51: 1076-9.

21. Abdelazez M, Quesnel P, Chan A, Yang $H$. Signal quality analysis of ambulatory electrocardiograms to gate false myocardial ischemia alarms. IEEE Trans Biomed Eng 2016. DOI:10.1109/ TBME.2016.2602283.

22. Landesberg G, Beattie WS, Mosseri M, Jaffe AS, Alpert JS Perioperative myocardial infarction. Circulation 2009; 119: 293644.

23. Mackey WC, Fleisher LA, Haider S, et al. Perioperative myocardial ischemic injury in high-risk vascular surgery patients: incidence and clinical significance in a prospective clinical trial. J Vasc Surg 2006; 43: 533-8.

24. $X u L, Y u C$, Jiang $J$, et al. Major adverse cardiac events in elderly patients with coronary artery disease undergoing noncardiac surgery: a multicenter prospective study in China. Arch Gerontol Geriatr 2015; 61: 503-9.

25. van Klei WA, Bryson GL, Yang H, Forster AJ. Effect of betablocker prescription on the incidence of postoperative myocardial infarction after hip and knee arthroplasty. Anesthesiology 2009; 111: 717-24.

26. Nesto RW, Kowalchuk GJ. The ischemic cascade: temporal sequence of hemodynamic, electrocardiographic and symptomatic expressions of ischemia. Am J Cardiol 1987; 59: 23C-30C. 